DOI:10.15171/ipp.2019.05

\title{
The accuracy of selected hematology and inflammatory indices for predicting preterm labor; a cross-sectional study
}

\author{
Farah Farzaneh $^{1(}$, Shamin Ghobadi ${ }^{1 *(\mathbb{D}}$, Abdorrahim Absalan $^{2}$ \\ 1Preventive Gynecology Research Center, Shahid Beheshti University of Medical Sciences, Tehran, Iran \\ ${ }^{2}$ Department of Medical Laboratory Sciences, Khomein University of Medical Sciences, Markazi Province, Iran
}

\section{*Correspondence to}

Shamin Ghobadi,

Email: sh.ghobadi2006@gmail.com

Received 4 March 2019

Accepted 1 April 2019

Published online 7 April 2019

Keywords: Differential diagnosis, Lymphocyte, Neutrophil, Preterm labor

\section{Abstract}

Introduction: The role of inflammatory indices has been suggested in preterm labor.

Objectives: The possible relationship of some inflammatory and hematological markers were investigated as predictors of preterm labor.

Patients and Methods: Around 110 full-term and 109 preterm women were randomly enrolled. According to the gestational age at delivery, they were divided into two groups including $<37$ weeks and $\geq 37$ weeks pregnancies. The patients' age, body mass index (BMI), history of smoking were recorded. Selected hematological parameters, erythrocyte sedimentation rate (ESR) and high-sensitive C-reactive protein (hsCRP) were measured. Comparison of groups, the odd's ratio and accuracy of each index were evaluated and assessed statistically.

Results: Overall, 110 full-term and 109 preterm mothers were evaluated. Mothers with preterm labor had higher WBC, hemoglobin, neutrophil proportion, neutrophil/lymphocyte ratio (NLR), platelet count, platelet/lymphocyte ratio (PLR), and ESR and also hs-CRP values. However, they had lower lymphocyte proportion than mothers with full-term delivery. Hs-CRP higher than $10.9 \mathrm{mg} / \mathrm{L}$ showed moderate sensitivity $(50.46 \%)$ instead of high specificity $(90.91 \%$ ), while ESR $>30 \mathrm{~mm}$ revealed $85.32 \%$ sensitivity and $93.64 \%$ specificity for predicting preterm labor. Lymphocyte ratio $\leq 22 \%$ and NLR $>3.21$ represented high sensitivity and plausible specificity. Hemoglobin $>10.8 \mathrm{~g} / \mathrm{dL}$, platelet count $>178000$ cells $/ \mu \mathrm{L}, \mathrm{PLR}>8.53$ and WBC $>7800$ cells $/ \mu \mathrm{L}$ showed adequate sensitivities with low to moderate specificities to predict preterm labor. Conclusion: Most of the investigated variables were associated with preterm delivery. The cut-off values obtained here may help obstetricians to predict preterm delivery, and therefore to manage its complications, costs, hazards and care problems.

Citation: Farzaneh F,
Ghobadi S, Absalan
A. The accuracy of
selected hematology and
inflammatory indices for
predicting preterm labor;
a cross-sectional study.
Immunopathol Persa.
2019;5(1):e05.
DOI:10.15171/
ipp.2019.05.

Citation: Farzaneh F, Ghobadi S, Absalan A. The accuracy of selected hematology and Immunopathol Pers DOl:10.15171/ ipp.2019.05

\section{Introduction}

Preterm labor is one of the main causes of morbidity and mortality in premature neonates (1). Pre-term deliveries (i.e. before the 37 th week of pregnancy) occurs in nearly $8 \%$ of all deliveries $(2,3)$. In addition, $75 \%$ of neonatal mortalities befall in preterm deliveries (4). The main risk factors of preterm labor include hypertension during pregnancy, placental, genital and anatomical problems, premature placental abruption or membrane bruising, multiple pregnancies, histories of abdominal surgery as well as premature delivery and abortion (5). The premature neonates' costs of care have been estimated at $\$ 30000$ in the United States (6). Therefore, preventing preterm delivery is important to manage its socioeconomical burden, as well as its complications. Preterm labor has a multifactorial etiology. Multiple

\section{Key point}

The cut-off values including hs-CRP $>10.9 \mathrm{mg} / \mathrm{L}$, ESR $>30 \mathrm{~mm}$, lymphocyte $\leq 22 \%$ and neutrophil/ lymphocyte ratio $>3.21$ harbor proper accuracy for predicting pre-term labor.

factors such as fetus endocrine dysfunction, as well as pathologic, inflammatory and infectious causes have been suggested to predispose to preterm labor.

Systemic inflammation alters absolute and relative neutrophil and lymphocyte counts. In this regard and in parallel to common indices such as C-reactive protein, neutrophil to lymphocyte ratio (NLR) or platelet to lymphocyte ratio (PLR) have also been introduced as potential inflammatory markers (7-9). Delivery pain itself provokes an inflammatory response in the body (10).

Copyright $\odot 2019$ The Author(s); Published by Nickan Research Institute. This is an open-access article distributed under the terms of the Creative Commons Attribution License (http://creativecommons.org/licenses/by/4.0), which permits unrestricted use, distribution, and reproduction in any medium, provided the original work is properly cited. 
On the other hand, increased total and differential white blood cell counts are observed in the primitive phase of delivery. Furthermore, the myometrium and cervix are infiltrated by inflammatory cells during delivery. Accordingly, these subclinical inflammatory events may mask other sources of infection or inflammation in pregnant women $(11,12)$. Routine clinical evaluations for diagnosis of preterm delivery (i.e. cervix length measurement using transvaginal sonography, fetal fibronectin assay and bacterial vaginosis evaluation) have not been well oriented for diagnosis of preterm delivery (13). In addition, these clinical evaluations are costly and time-consuming.

\section{Objectives}

In this study, we aimed to evaluate the diagnostic accuracy of routine para-clinical and laboratory parameters (including selected hematologic and inflammatory parameters) to predict preterm labor. Furthermore, we evaluated these parameters as potential risk factors for preterm labor.

\section{Patients and Methods}

Study protocol

This study was approved by the Ethical Committee of Shahid-Beheshti University of Medical Sciences. Singleton pregnant women with intact membrane, temperature $<38^{\circ} \mathrm{C}$, regular uterine contraction (4 times in every 20 minutes and 8 ones in every 60 minutes) with cervical effacement $\geq 80 \%$ or cervical dilatation $>2 \mathrm{~cm}$ that admitted to Imam-Hossein hospital, Tehran, Iran (September 2016 to September 2018) were enrolled in our study. Chronic inflammatory disease (including ulcerative colitis, Crohn's disease, and rheumatoid arthritis), ceasing labor pain and fetal tachycardia were the exclusion criteria. The women were categorized based on the standard criteria, into either preterm (24-37 weeks) or term (37-42 weeks) groups. The patients willing to participate were requested to sign an informed consent.

The patient's demographic data was gathered by interviewing the mothers or exploring their medical records. The patients' age, body mass index (BMI) before pregnancy and at delivery time, history of smoking, education were recorded. Selected hematological parameters, erythrocyte sedimentation rate (ESR) and high-sensitive C-reactive protein (hs-CRP) were measured.

The whole blood samples for laboratory measurements were collected from each participant at admission. Hematologic indices were determined using KX-21 Sysmex automated hematology analyzer. ESR was determined using an automated ESR reader (ESR STAT ${ }^{\mathrm{m}}$ PLUS). CRP serum level was measured using immunoturbidimetric assays (Pars Azmun Co. Iran).

\section{Ethical issues}

The research followed the tenets of the Declaration of
Helsinki and its later amendments. Patients gave their written and informed consent to participate in this investigation by completing the consent form. Permission for conducting this investigation was obtained from Research Department of Shahid Beheshti University of Medical Sciences as the residency thesis of Shamin Ghobadi (M281) in the department of gynecology. All information about individuals was coded and kept confidential. This study has an ethical code of IR.SBMU.MSP.REC.1397.228.

\section{Statistical analysis}

Statistical analysis was done in SPSS version 24 and MedCalc statistical Software version 15.8 (14). For quantitative variables with non-normal distribution; 25th, 50th and 75th percentiles plus minimum and maximum values were reported along with the mean \pm SD. Mann-Whitney $\mathrm{U}$ test was applied to compare the variables between fullterm and pre-term groups. Odds ratios were calculated to estimate potential risk factors of pre-term labor. The sensitivity, specificity, positive predictive value (PPV) and negative predictive value (NPV) were determined for the cut-off values obtained by receiver operating characteristic (ROC) curve analysis. The area under ROC curves (AUC) were also reported for these variables. Pearson correlation was used to assess correlations between the variables. The confidence interval was considered equal to $95 \%$ in all the statistical analysis.

\section{Results}

In total, 225 singleton pregnant women enrolled in our study, among them 6 were excluded due to stop their labor pain. Therefore, 110 term and 109 preterm deliveries were investigated in our study. The distribution of educational levels was significantly different between the mothers with preterm and full-term labors. In this study we found a significant association between mothers' age at the pregnancy and the risk of preterm labor. The values of WBC, hemoglobin, relative neutrophil count (\%), NLR, platelet count, platelet count, PLR, ESR and hs-CRP were significantly higher in preterm group $(P<0.05$ for all comparisons). On the other hand, the mean lymphocyte percentage was significantly higher in the term group $(P<0.05)$.

Table 1 shows the comparison of the variables between full-term and preterm deliveries, as well as their odds ratios associated with the risk of preterm labor. The highest odds ratio for preterm delivery was related to NLR followed by platelet count, PLR and hemoglobin. The obtained odd ratios revealed that higher values of WBC, hemoglobin, neutrophil \%, NLR, platelet count, platelet count, PLR, ESR and hs-CRP, or lower lymphocyte \% were potential risk factors for preterm labor. The frequencies of cesarean were $34.9 \%$ and $51 \%$ in mothers with preterm and fullterm deliveries respectively ( $P=0.1107)$. There were no significant deviations in the distributions of cigarette smoking history, employment status, gestational diabetes, 
Table 1. Distribution and odd ratios of selected hematologic and inflammatory indices in mothers with term and preterm delivery

\begin{tabular}{|c|c|c|c|c|c|c|c|c|c|}
\hline & \multirow{2}{*}{ Group } & \multirow{2}{*}{ Mean \pm SD } & \multirow{2}{*}{ Min } & \multirow{2}{*}{ Max } & \multicolumn{3}{|c|}{ Percentiles } & \multirow{2}{*}{$P$ value } & \multirow{2}{*}{$\begin{array}{l}\text { Odds ratio }(95 \% \\
\text { CI) } P \text { value }\end{array}$} \\
\hline & & & & & $25^{\text {th }}$ & $50^{\text {th }}$ (Median) & $75^{\text {th }}$ & & \\
\hline \multirow{2}{*}{ Age $(y)$} & Preterm & $27.61 \pm 5.14$ & 18 & 44 & 24 & 27 & 31 & \multirow{2}{*}{0.003} & \multirow{2}{*}{$\begin{array}{r}1.1083(1.0413 \text { to } \\
1.1797) P=0.0012\end{array}$} \\
\hline & Term & $25.53 \pm 3.86$ & 18 & 35 & 22.75 & 25 & 28 & & \\
\hline \multirow{2}{*}{ WBC (cells $/ \mu \mathrm{L})$} & Preterm & $9302.56 \pm 1467.40$ & 6300 & 13800 & 8400 & 9100 & 9900 & \multirow{2}{*}{0.000} & \multirow{2}{*}{$\begin{array}{l}1.0006(1.0004 \text { to } \\
1.0008) P<0.0001\end{array}$} \\
\hline & Term & $8056.63 \pm 1550.95$ & 5600 & 13100 & 6900 & 7650 & 8800 & & \\
\hline \multirow{2}{*}{ Hemoglobin $(\mathrm{g} / \mathrm{dL})$} & Preterm & $11.88 \pm 0.97$ & 9.8 & 13.9 & 11.2 & 12 & 12.6 & \multirow{2}{*}{0.037} & \multirow{2}{*}{$\begin{array}{l}1.2970(1.0186 \text { to } \\
1.6515) P=0.0349\end{array}$} \\
\hline & Term & $11.56 \pm 1.24$ & 9.2 & 13.9 & 10.67 & 11.6 & 12.6 & & \\
\hline \multirow{2}{*}{ Neutrophil \% } & Preterm & $76.77 \pm 5.12$ & 59.2 & 89 & 74 & 78 & 79 & \multirow{2}{*}{0.000} & \multirow{2}{*}{$\begin{array}{l}1.2015 \text { (1.1301 to } \\
1.2773) P<0.0001\end{array}$} \\
\hline & Term & $72 \pm 4.98$ & 63.8 & 81.1 & 68 & 70.01 & 77.2 & & \\
\hline \multirow{2}{*}{ Lymphocyte \% } & Preterm & $19.34 \pm 3.36$ & 8.7 & 33.3 & 18 & 20 & 21.3 & \multirow{2}{*}{0.000} & \multirow{2}{*}{$\begin{array}{l}0.7291(0.6574 \text { to } \\
0.8086) p<0.0001\end{array}$} \\
\hline & Term & $23.17 \pm 3.97$ & 15.5 & 32.2 & 19.87 & 23.3 & 26.9 & & \\
\hline \multirow{2}{*}{ NLR } & Preterm & $4.18 \pm 1.39$ & 1.78 & 10.18 & 3.5 & 3.90 & 4.33 & \multirow{2}{*}{0.000} & \multirow{2}{*}{$\begin{array}{l}3.7980(2.4163 \text { to } \\
5.9700) p<0.0001\end{array}$} \\
\hline & Term & $3.23 \pm 0.77$ & 2.02 & 5.16 & 2.7 & 3.04 & 3.87 & & \\
\hline \multirow{2}{*}{$\begin{array}{l}\text { Platelet count }\left(\times 10^{3}\right. \\
\text { cells } / \mu \mathrm{L})\end{array}$} & Preterm & $211.71 \pm 41.57$ & 115 & 312 & 188 & 200 & 222.5 & \multirow{2}{*}{0.000} & \multirow{2}{*}{$\begin{array}{l}1.01261 .0056(\text { to } \\
1.0196) p=0.0004\end{array}$} \\
\hline & Term & $190.30 \pm 41.89$ & 108 & 310 & 166 & 188 & 210 & & \\
\hline \multirow{2}{*}{ PLR } & Preterm & $11.37 \pm 3.67$ & 4.77 & 35.45 & 9.24 & 10.5 & 12.8 & \multirow{2}{*}{0.000} & \multirow{2}{*}{$\begin{array}{l}1.5208(1.3255 \text { to } \\
1.7447) p<0.0001\end{array}$} \\
\hline & Term & $8.5 \pm 2.46$ & 3.61 & 14.9 & 6.7 & 8.41 & 10.24 & & \\
\hline \multirow{2}{*}{$\mathrm{ESR}(\mathrm{mm})$} & Preterm & $46.07 \pm 14.94$ & 10 & 78 & 35.5 & 45 & 56 & \multirow{2}{*}{0.000} & 1.2147 (1.1537 to \\
\hline & Term & $19.86 \pm 7.44$ & 7 & 45 & 14.75 & 20 & 23 & & $1.2790) p<0.0001$ \\
\hline hs-CRP (IU/mL) & Preterm & $10.75 \pm 5.09$ & 2 & 28 & 8 & 11 & 12 & 0.000 & 1.1177 (1.0486 to \\
\hline & Term & $8.11 \pm 5.25$ & 2 & 34.4 & 4.67 & 7.7 & 9.8 & & 1.1914) $P=0.0023$ \\
\hline
\end{tabular}

ESR, erythrocyte sedimentation rate; hs-CRP, high sensitive C-reactive protein; SD, Standard deviation; NLR, Neutrophil/Lymphocyte ratio; PLR, Platelet/ Lymphocyte ratio; PLR, Platelet/Lymphocyte ratio; WBC, white blood cell.

metritis or hypothyroidism between preterm and fullterm mothers (Table 2).

We evaluated the diagnostic accuracy of each studied variable for predicting preterm delivery. The diagnostic accuracy was determined using ROC analysis (Figure 1). Youden index was applied to obtain proper cut-off values. ROC analysis showed that the studied hematological parameters had the least accuracies for predicting preterm labor. On the other hand, the hs-CRP value $>10.9 \mathrm{mg} / \mathrm{L}$, represented moderate $(50.46 \%)$ sensitivity and high (90.91\%) specificity. The hs-CRP also revealed high (84.6\%) PPV, although lower (64.9\%) NPV for preterm delivery. The AUC $=0.940$ was obtained for ESR also indicated a high predictability potential for parameter delivery. ESR represented sensitivity, specificity, PPV, and NPV values of $85.32 \%, 93.64 \%, 93.0 \%$ and $86.6 \%$ respectively. At the respective cut off values of $\leq 22 \%$ and $>3.21$, lymphocyte

Table 2. Distribution and odd ratios of demographic and clinical variables in mothers with full-term and preterm labor

\begin{tabular}{llcc}
\hline & & Preterm & Term \\
\hline \multirow{4}{*}{$\begin{array}{lllc}\text { Smoking } \\
\text { history }\end{array}$} & No & $74(49.7 \%)$ & $75(50.3 \%)$ \\
& $P$ value & $35(50.0 \%)$ & $35(50.0 \%)$ \\
\cline { 2 - 3 } Occupation & Odds ratio & $0.9867(0.5591$ to 1.7413$) P=0.9631$ \\
& Busy & $53(51.0 \%)$ & $51(49.0 \%)$ \\
& Housewife & $56(48.7 \%)$ & $59(51.3 \%)$ \\
& $P$ value & & 0.8418 \\
& Odds ratio & $0.9133(0.5373$ to 1.5526$) P=0.7377$ \\
\hline
\end{tabular}

$\%$ and NLR represented high sensitivities with respectively lower specificities and NPVs for predicting preterm labor. The hemoglobin, platelet count, platelet count, PLR and WBC represented good sensitivities against low to moderate specificities at their optimal cut-off points for predicting preterm delivery (Table 3 ).

Table 4 shows the results of Pearson's correlation analysis for estimating correlations between the studied variables.

In the current study, the mothers with preterm labor were further divided into two groups including early-preterm and late-preterm. Early preterm was defined as delivery at up to the week 33 plus 6 days (i.e. the weeks 28 to $33+$ 6 days). Late-preterm; on the other hand, was defined as delivery between the weeks 34 to 36 of pregnancy. Overall, 27 and 82 mothers had early preterm and late-preterm labors respectively. There were no significant differences between early and late preterm groups regarding the studied inflammatory and hematologic parameters (Figures 2 and 3).

\section{Discussion}

Different studies have been dedicated to identify potential risk factors of pre-term labor. In the current study, we assessed the diagnostic and predictive validities of some hematologic and inflammatory indices as potential risk factors of pre-term labor. Considering clinical and demographical parameters, no significant associations were obtained between mothers' education, history of smoking, gestational diabetes, metritis, and 

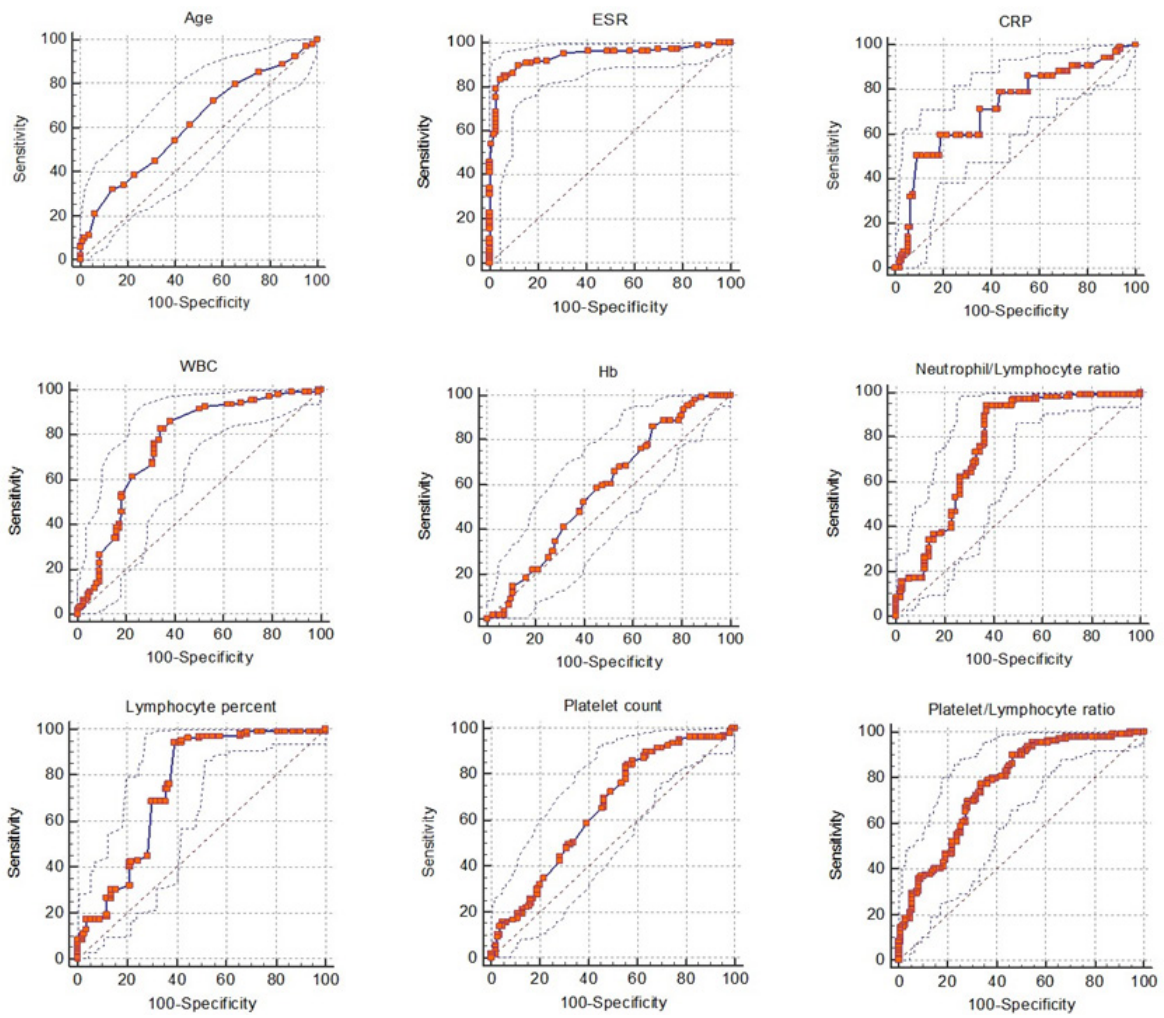

Figure 1. Receiver operating curve (ROC) analysis for the studied parameters and their area under curve (AUC), sensitivity and specificity. As indicated, ESR and NLR represented higher validities for predicting preterm labor. Furthermore, WBC, lymphocyte\%, platelet count, and platelet/lymphocyte ratio showed appropriate AUC values for diagnosis of pre-term delivery.

hypothyroidism and also preterm labor. This study evaluated a relatively low number of subjects in some categories (such as mothers diagnosed with gestational diabetes, metritis and hypothyroidism) limiting the power of the study. The results of the current study showed that higher pregnancy age, lower hemoglobin concentration, higher neutrophil \%, platelet count, NLR, and platelet count, PLR could predict preterm labor. Furthermore, ESR and hs-CRP inflammatory parameters were significantly higher in mothers with preterm labor than those with fullterm deliveries. According to these findings, most of the investigated variables can be utilized as the early indicators of preterm labor.

Most mothers with full-term labor had non-academic

Table 3. ROC analysis for selected variables along with optimal cut-off points and their accuracy indices for predicting preterm labor

\begin{tabular}{|c|c|c|c|c|c|c|}
\hline Variable & $\begin{array}{l}\mathrm{AUC} \pm \mathrm{SE}(95 \% \mathrm{Cl}) \\
P \text { value }\end{array}$ & $\begin{array}{c}\text { Cut-off * value; } \\
\text { Disease is present if }\end{array}$ & $\begin{array}{l}\text { Sensitivity } \\
\%\end{array}$ & $\begin{array}{l}\text { Specificity } \\
\%\end{array}$ & $\begin{array}{c}\text { PPV } \\
(95 \% \mathrm{CI})\end{array}$ & $\begin{array}{c}\text { NPV } \\
(95 \% \mathrm{CI})\end{array}$ \\
\hline hs-CRP (mg/L) & $\begin{array}{l}0.722 \pm 0.0349(0.658 \text { to } 0.781) \\
P<0.0001\end{array}$ & $\begin{array}{c}>10.9 \\
(>9.9:>10.9)\end{array}$ & 50.46 & 90.91 & $\begin{array}{c}84.6 \\
(73.5-92.4)\end{array}$ & $\begin{array}{c}64.9 \\
(56.8-72.4)\end{array}$ \\
\hline $\mathrm{ESR}(\mathrm{mm})$ & $\begin{array}{l}0.940 \pm 0.0172 \text { (0.900 to } 0.967) \\
P<0.0001\end{array}$ & $\begin{array}{c}>30 \\
(>27:>34)\end{array}$ & 85.32 & 93.64 & $\begin{array}{c}93.0 \\
(86.1-97.1)\end{array}$ & $\begin{array}{c}86.6 \\
(79.1-92.1)\end{array}$ \\
\hline Hemoglobin $(\mathrm{g} / \mathrm{dL})$ & $\begin{array}{l}0.582 \pm 0.0387 \text { ( } 0.513 \text { to } 0.648) \\
P=0.0350\end{array}$ & $\begin{array}{c}>10.8 \\
(>9.9:>12.2)\end{array}$ & 86.24 & 31.82 & $\begin{array}{c}55.6 \\
(47.8-63.2)\end{array}$ & $\begin{array}{c}70.0 \\
(55.4-82.1)\end{array}$ \\
\hline Lymphocyte\% & $\begin{array}{l}0.751 \pm 0.0342 \text { (0.688 to } 0.807) \\
P<0.0001\end{array}$ & $\begin{array}{c}\leq 22 \\
(\leq 22: \leq 22.7)\end{array}$ & 94.50 & 60.91 & $\begin{array}{c}70.5 \\
(62.4-77.8)\end{array}$ & $\begin{array}{c}91.8 \\
(83.0-96.9)\end{array}$ \\
\hline NLR & $\begin{array}{l}0.765 \pm 0.0333 \text { (0.703 to } 0.820) \\
P<0.0001\end{array}$ & $\begin{array}{c}>3.21 \\
(>3.2:>3.25)\end{array}$ & 94.50 & 62.73 & $\begin{array}{c}71.5 \\
(63.4-78.7)\end{array}$ & $\begin{array}{c}92.0 \\
(83.4-97.0)\end{array}$ \\
\hline $\begin{array}{l}\text { Platelet count } \\
\left(\times 10^{3} \text { cells } / \mu \mathrm{L}\right)\end{array}$ & $\begin{array}{l}0.649 \pm 0.0371(0.582 \text { to } 0.713) \\
P=0.0001\end{array}$ & $\begin{array}{c}>178 \\
(>156:>182)\end{array}$ & 86.24 & 41.82 & $\begin{array}{c}59.5 \\
(51.4-67.2)\end{array}$ & $\begin{array}{c}75.4 \\
62.7-85.5\end{array}$ \\
\hline PLR & $\begin{array}{l}0.770 \pm 0.0316 \text { (0.708 to } 0.824) \\
P<0.0001\end{array}$ & $\begin{array}{c}>8.53 \\
(>7.63:>9.6)\end{array}$ & 89.91 & 53.64 & $\begin{array}{c}65.8 \\
(57.6-73.3)\end{array}$ & $\begin{array}{c}84.3 \\
(73.6-91.9)\end{array}$ \\
\hline WBC (cells/ $/ \mu \mathrm{L})$ & $\begin{array}{l}0.760 \pm 0.0334 \text { ( } 0.698 \text { to } 0.815) \\
P<0.0001\end{array}$ & $\begin{array}{c}>7800 \\
(>7400:>8000)\end{array}$ & 86.24 & 61.82 & $\begin{array}{c}69.1 \\
(60.6-76.8)\end{array}$ & $\begin{array}{c}81.9 \\
(72.0-89.5)\end{array}$ \\
\hline
\end{tabular}

AUC, Area under the ROC curve; ESR, erythrocyte sedimentation rate; hs-CRP, high sensitive C-reactive protein; SE, Standard Error; NLR, Neutrophil/ Lymphocyte ratio; NPV, Negative predictive value; PLR, Platelet/Lymphocyte ratio; PPV, Positive predictive value; PLR, Platelet/Lymphocyte ratio; WBC, white blood cell.

*Calculated by Youden index. 
Table 4. Correlation coefficients between the study variables

\begin{tabular}{|c|c|c|c|c|c|c|c|c|c|c|}
\hline & & WBC & Hemoglobin & Neutrophil \% & Lymphocyte \% & NLR & Platelet count & PLR & ESR & hs-CRP \\
\hline \multirow{2}{*}{ Age } & $\mathrm{R}$ & $0.164^{*}$ & -0.005 & 0.105 & $-0.177^{\ddagger}$ & 0.083 & 0.080 & 0.103 & 0.070 & 0.074 \\
\hline & $P$ & 0.015 & 0.94 & 0.121 & 0.009 & 0.22 & 0.239 & 0.127 & \multirow{2}{*}{$\begin{array}{l}0.306 \\
0.291^{\ddagger}\end{array}$} & \multirow{2}{*}{$\begin{array}{l}0.279 \\
0.029\end{array}$} \\
\hline \multirow{2}{*}{ WBC count } & $\mathrm{R}$ & & 0.092 & $0.246^{\ddagger}$ & $-0.304^{\ddagger}$ & $0.236^{\ddagger}$ & $0.239^{\ddagger}$ & $0.305^{\ddagger}$ & & \\
\hline & $P$ & & 0.173 & 0.000 & 0.000 & 0.000 & 0.000 & 0.000 & \multirow{2}{*}{$\begin{array}{l}0.000 \\
0.038\end{array}$} & \multirow{2}{*}{$\begin{array}{l}0.672 \\
0.069\end{array}$} \\
\hline \multirow{2}{*}{ Hemoglobin } & $\mathrm{R}$ & & & $0.162^{*}$ & $-0.146^{*}$ & $0.184^{\ddagger}$ & 0.079 & $0.178^{\ddagger}$ & & \\
\hline & $P$ & & & 0.016 & 0.031 & 0.006 & 0.242 & 0.008 & \multirow{2}{*}{$\begin{array}{l}0.575 \\
0.264^{\ddagger}\end{array}$} & \multirow{2}{*}{$\begin{array}{l}0.308 \\
0.231^{\neq}\end{array}$} \\
\hline \multirow{2}{*}{ Neutrophil percent } & $\mathrm{R}$ & & & & $-0.799^{\ddagger}$ & $0.805^{\ddagger}$ & 0.104 & $0.570^{\ddagger}$ & & \\
\hline & $P$ & & & & 0.000 & 0.000 & 0.126 & 0.000 & \multirow{2}{*}{$\begin{array}{l}0.000 \\
-0.273^{\ddagger}\end{array}$} & \multirow{2}{*}{$\begin{array}{l}0.001 \\
-0.205^{\ddagger}\end{array}$} \\
\hline \multirow{2}{*}{ Lymphocyte percent } & $\mathrm{R}$ & & & & & $-0.893^{\neq}$ & $-0.157^{*}$ & $-0.720^{\ddagger}$ & & \\
\hline & $P$ & & & & & 0.000 & 0.02 & 0.000 & \multirow{2}{*}{$\begin{array}{l}0.000 \\
0.199^{\ddagger}\end{array}$} & \multirow{2}{*}{$\begin{array}{l}0.002 \\
0.340^{\ddagger}\end{array}$} \\
\hline \multirow{2}{*}{ NLR } & $\mathrm{R}$ & & & & & & 0.077 & $0.752^{\ddagger}$ & & \\
\hline & $P$ & & & & & & 0.259 & 0.000 & 0.003 & 0.000 \\
\hline \multirow{2}{*}{ Platelet count } & $\mathrm{R}$ & & & & & & & $0.677^{\ddagger}$ & $0.140^{*}$ & $-0.136^{*}$ \\
\hline & $P$ & & & & & & & 0.000 & \multirow{2}{*}{$\begin{array}{l}0.038 \\
0.219^{\ddagger}\end{array}$} & \multirow{2}{*}{$\begin{array}{l}0.044 \\
0.143^{*}\end{array}$} \\
\hline \multirow{2}{*}{ PLR } & $\mathrm{R}$ & & & & & & & & & \\
\hline & $P$ & & & & & & & & 0.001 & \multirow{2}{*}{$\begin{array}{l}0.035 \\
0.223^{\ddagger}\end{array}$} \\
\hline \multirow{2}{*}{ ESR } & $\mathrm{R}$ & & & & & & & & & \\
\hline & $P$ & & & & & & & & & 0.001 \\
\hline
\end{tabular}

ESR, erythrocyte sedimentation rate; hs-CRP, high sensitive C-reactive protein; NLR, Neutrophil/Lymphocyte ratio; PLR, Platelet/Lymphocyte ratio; WBC, white blood cell.

¥Correlation is significant at the 0.01 level (2-tailed).

*Correlation is significant at the 0.05 level (2-tailed).

educations proposing that mothers with higher educations may be at higher risk for preterm labor. Nevertheless, this may also be due to higher tendencies of high-educated mothers to be pregnant in an older age which predispose them to preterm delivery. In fact, women with higher educational levels tend to marry in an older age, since older age can subsequently expose them to the higher risk of preterm labor.

Among hematologic parameters, NLR was the best predictor of preterm labor. Increased NLR resulted in 3.79 (95\% CI: .41 to 5.97) folds elevated risk of preterm delivery. Furthermore, mothers with higher platelet count, PLR also represented a higher risk for preterm delivery (odd ratio $=$

\subsection{2, 95\% CI: 1.32 to 1.74$)$}

Considering the accuracy parameters (i.e. sensitivity, specificity, PPV, and NPV), ESR and NLR delivered the highest diagnostic validities. At the cut-off values of ESR $>30 \mathrm{~mm}$ and NLR $>3.21$, these two parameters represented relatively high sensitivities, specificities, PPVs and NPVs. Nonetheless, neither of the evaluated parameters showed significantly different distributions in mothers with early and late preterm deliveries. This phenomenon suggests similar pathologic and physiologic events underlying early and late preterm deliveries.

Bozoklu Akkar et al showed that NLR was significantly higher in mothers with preterm labor (7). Similar finding

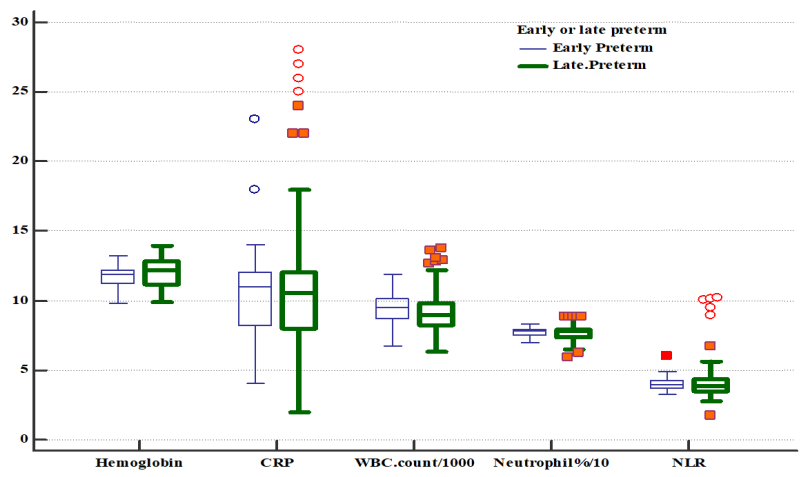

Figure 3. Comparison of hemoglobin, hs-CRP, WBC count, neutrophil\% and neutrophil/lymphocyte\% between mothers with early and late preterm deliveries. Statistical analysis showed no significant differences between early and late preterm deliveries regarding these variables ( $P>0.05$ for all comparisons, Mann-Whitney $U$ test were). 
was evident in our study with more frequent preterm labors seen in mothers with higher NLR. These findings suggest NLR index is a helpful diagnostic and predictive marker for preterm labor. Nevertheless, the cut-off value obtained for NLR (i.e. >3.21) should be evaluated in future studies. Other studies have shown that both NLR and PLR maybe useful in predicting the pre-term labor $(15,16)$. Kim et al reported the respective $71.4 \%, 77.9 \%, 80.7 \%$, and $67.8 \%$ sensitivity, specificity, PPV, and NPV for NLR at the cutoff value of 6.48 (16). In our study, regarding the cut off value of $>3.21$, NLR represented $94.50 \%, 62.73 \%, 71.5 \%$ and $92.0 \%$ sensitivity, specificity, PPV and respectively. In comparison, the accuracy values obtained in our study indicated higher sensitivity and NPV than Kim et al which may be due to the different exploited cut off points.

In addition to NLR, Kim et al also evaluated the accuracy criteria of hs-CRP for differential diagnosis of placental inflammatory response. At the cutoff point of $7.46 \mathrm{mg} / \mathrm{L}$, hs-CRP represented the sensitivity, specificity, PPV and NPV of $56.8 \%, 82.9 \%, 81.1 \%$ and $59.8 \%$, respectively. In addition, hs-CRP rendered the AUC of 0.727 (95\% CI, 0.679-0.776) (16). In the current study, using the cut-off point of $>10.9 \mathrm{mg} / \mathrm{L}$, hs-CRP showed sensitivity, specificity, PPV, and NPV of $50.46 \%, 90.91,84.6 \%$ and $64.9 \%$ respectively. Furthermore, hs-CRP revealed the AUC of 0.722 (95\% CI, 0.658-0.781) at this threshold. Accordingly, both the recent studies implied the importance of this acute phase protein as a diagnostic marker in pregnant women, one for inflammatory response (i.e. Kim et al) and the other for preterm labor (i.e. our study). Furthermore, we also described that ESR, as another inflammatory marker, represented even better accuracy indices than hs-CRP and NLR for predicting preterm labor.

In their study, Daglar et al showed no significant difference in the mean values of platelet count, PLR between mothers with preterm or full term deliveries negating this marker as a good predictor of preterm labor (15). In contrast to the study of Daglar et al, we here identified platelet count, PLR as a significant risk factor for preterm labor (odd ratio $=1.5208 ; 95 \% \mathrm{CI}=1.3255-1.7447$, $P<0.0001)$. Moreover, ROC analysis showed an AUC value of $0.770(95 \% \mathrm{CI}=0.708-0.824)$ for platelet count, PLR at the cut-off point of $>8.53$. In this threshold, platelet count, PLR revealed $89.91 \%, 53.64 \%, 65.8 \%$ and $84.3 \%$ sensitivity, specificity, PPV, and NPV respectively. Based on our observation, platelet count, PLR could be a valuable predictor of preterm labor. In line with our findings, Daglar et al also reported that NLR and hs-CRP were significantly different between mothers with full-term and preterm labor. In accordance with our study, Daglar et al also reported insignificant differences between mothers with preterm and full-term labors regarding demographic variables such as maternal age, weight, and height, as well as the number of pregnancies and educational status (15). Collectively, inflammatory responses in preterm labor seem to be independent from demographic variables.
On the other hand, platelet count, PLR and NLR may be influenced by ethnicity which should be considered when interpreting these parameters.

\section{Conclusion}

In the present study, we evaluated the diagnostic accuracy of routine clinical, para-clinical, and demographical variables for predicting preterm labor. Most of the evaluated variables delivered potentially valuable predictors of preterm labor. The measurement of hematology and inflammatory indices for predicting preterm labor may be helpful to solve the major problem to identify true preterm labor which leads to preterm delivery. To confirm the diagnostic validity of these markers; however, further investigations are needed in other countries and ethnic groups. In conclusion, hs-CRP, ESR, platelet count, PLR and NLR rendered reliable markers for diagnosis and predicting preterm labor. In addition, the optimal cut-off points reported for these variables may be helpful in guiding obstetricians to preterm delivery. Nonetheless, these are suggested to be further evaluated and validated in clinical settings. Regarding the complications, costs, hazards and care problems of preterm delivery, it is recommended to recruit the evaluated variables as potential biomarkers and predictors of pre-term labor.

\section{Limitations of the study}

This study was conducted on a limited proportion of patients. We suggest further studies on this subject.

\section{Acknowledgments}

We would like to thanks nurses, laboratory staff and medical residents who help us performing the study. In addition, we thank dear patients who let us evaluate them in this investigation.

\section{Authors' contribution}

This manuscript is a part of residency thesis by SG in gynecology and is approved by Shahid Beheshti University of Medical Sciences. FF was the supervisor, theory developer and manager of the study. SG has prepared the research proposal, followed the approval of the thesis, gathered data, coordinate the work, and prepared the article. Statistical analysis and revision of the manuscript were done by AA. All authors read and signed the final version of paper.

Conflicts of interest

Authors declare there is not any conflict of interest.

Ethical considerations

Ethical issues (including plagiarism, data fabrication, double publication) have been completely observed by the authors.

\section{Funding/Support}

This work is financially supported by Shahid Beheshti University of Medical Sciences research department with the approval code $281 \mathrm{M}$

\section{References}

1. Beck S, Wojdyla D, Say L, Betran AP, Merialdi M, Requejo JH, et al. The worldwide incidence of preterm birth: a systematic review of maternal mortality and morbidity. Bull World Health 
Organ. 2010;88:31-8. doi: 10.2471/BLT.08.062554.

2. Vogel JP, Chawanpaiboon S, Moller AB, Watananirun K, Bonet $M$, Lumbiganon P. The global epidemiology of preterm birth. Best Pract Res Clin Obstet Gynaecol. 2018;52:3-12. doi: 10.1016/j.bpobgyn.2018.04.003.

3. Lau E, DeFaria Yeh D. Management of high risk cardiac conditions in pregnancy: Anticoagulation, severe stenotic valvular disease and cardiomyopathy. Trends Cardiovasc Med. 2019;29:155-61. doi: 10.1016/j.tcm.2018.07.009.

4. Goldenberg RL. The management of preterm labor. Obstetrics Gynecology. 2002;100:1020-37. doi: 10.1016/S00297844(02)02212-3.

5. Romero R, Dey SK, Fisher SJ. Preterm labor: one syndrome, many causes. Science. 2014;345:760-5. doi: 10.1126/ science.1251816.

6. Kinney MV, Lawn JE, Howson CP, Belizan J. 15 million preterm births annually: what has changed this year? Reprod Health. 2012;9:28. doi: 10.1186/1742-4755-9-28.

7. Bozoklu Akkar O, Sancakdar E, Karakus S, Yildiz C, Akkar I, Arslan M, etal. Evaluation of maternal serum 25-hydroxyvitamin $d$, paraoxonase 1 levels, and neutrophil-to-lymphocyte ratio in spontaneous preterm birth. Med Sci Monit. 2016;22:1238-43. doi: 10.12659/MSM.897983.

8. Kim DS, Shin D, Lee MS, Kim HJ, Kim DY, Kim SM, et al. Assessments of neutrophil to lymphocyte ratio and platelet to lymphocyte ratio in Korean patients with psoriasis vulgaris and psoriatic arthritis. J Dermatol. 2016;43:305-10. doi: 10.1111/346-8138.13061.

9. Torun S, Tunc BD, Suvak B, Yildiz H, Tas A, Sayilir A, et al. Assessment of neutrophil-lymphocyte ratio in ulcerative colitis: a promising marker in predicting disease severity. Clin Res Hepatol Gastroenterol. 2012;36:491-7. doi: 10.1016/j. clinre.2012.06.004.

10. Roos C, Schuit E, Scheepers HC, Bloemenkamp KW, Bolte AC, Duvekot $\mathrm{HJ}$, et al. Predictive factors for delivery within 7 days after successful 48-hour treatment of threatened preterm labor. AJP Rep. 2015;5:e141-9. doi: 10.1055/s-0035-1552930.

11. Campbell MK, Challis JR, DaSilva O, Bocking AD. A cohort study found that white blood cell count and endocrine markers predicted preterm birth in symptomatic women. J Clin Epidemiol. 2005;58:304-10. doi: 10.1016/j. jclinepi.2004.06.015.

12. Romero R, Miranda J, Chaiworapongsa T, Korzeniewski SJ, Chaemsaithong P, Gotsch F, et al. Prevalence and clinical significance of sterile intra-amniotic inflammation in patients with preterm labor and intact membranes. Am J Reprod Immunol. 2014;72:458-74. doi: 10.1111/aji.12296.

13. Balta S, Demırkol S, Arslan Z, Demır M, Ozturk C. The neutrophil lymphocyte ratio in patients with ST segment elevation myocardial infarction. Eur Rev Med Pharmacol Sci. 2014;18:141.

14. Schoonjans F. Medcalc statistics for biomedical research: software manual. 2016:295.

15. Daglar H, Kirbas A, Kaya B, Kilincoglu F. The value of complete blood count parameters in predicting preterm delivery. Eur Rev Med Pharmacol Sci. 2016;20:801-5.

16. Kim M-A, Lee YS, Seo K. Assessment of predictive markers for placental inflammatory response in preterm births. PloS One. 2014;9:e107880. doi: 10.1371/journal.pone.0107880. 